\title{
Esthetic Prosthetic Restorations: Reliability and Effects on Antagonist Dentition
}

\author{
Elie E. Daou*
}

Department of Prosthodontics, School of Dentistry, Lebanese University, Beirut, Lebanon

\begin{abstract}
Recent advances in ceramics have greatly improved the functional and esthetic properties of restorative materials. New materials offer an esthetic and functional oral rehabilitation, however their impact on opposing teeth is not welldocumented. Peer-reviewed articles published till December 2014 were identified through Pubmed (Medline and Elsevier). Scientifically, there are several methods of measuring the wear process of natural dentition which enhances the comparison of the complicated results. This paper presents an overview of the newly used prosthetic materials and their implication on antagonist teeth or prostheses, especially emphasizing the behavior of zirconia restorations.
\end{abstract}

Keywords: Abrasion, antagonist, esthetic restorations.

\section{INTRODUCTION}

As the popularity of esthetic dentistry increases, growing number of new materials are introduced to the market. These new materials, that are alternative to metal-ceramics, are a delicate combination of scientific principles and artistic abilities. In general all ceramic restorative systems can be classified as: (1) traditional feldspathic porcelain, (2) pressable ceramics, (3) infiltrated ceramics, (4) milled ceramics. Protecting the natural dentition and providing an illusion of reality require the practitioner to choose the correct ceramic system.

This article explored the current materials as a result of an electronic search, during December 2014, through PubMed and Elsevier. Peer-reviewed articles were targeted. The following key-words were used: Restorations, esthetics, mechanics, wear resistance, abrasiveness, prostheses resistance, restorations wear. Available full-text articles were read. No hand search was driven.

\section{CURRENT RESTORATIVE MATERIALS}

Metal-ceramic prostheses are considered as the goldstandard in dentistry, with reasonable esthetics [1]. Longterm structural performance is well documented [2,3]. Highgold alloys are still classified as alloys of choice, with high tensile strength and fracture toughness, resistance to wear (low friction coefficients), and resistance to corrosion in the oral environment [4].

All-ceramic dental materials can demonstrate very different material properties. This can be related to variations in their chemical composition as well as in their structures [5]. Excellent esthetic characteristics and optimal mechanical properties are mandatory for an ideal all-ceramic material.

*Address correspondence to this author at the Department of Prosthodontics, School of Dentistry, Lebanese University, Beirut, Lebanon;

Tel: +9619440445; E-mails: dreliedaou@yahoo.com,

dreliedaou@gmail.com
Flexural strength, fracture toughness and limited crack propagation at the functional and parafunctional load conditions ensure lifetime serviceability [6]. To date, an inverse proportion between strength (i.e., the mechanical performance) and optical properties (i.e., the esthetic appearance) remains a predominant equation. Three different groups of ceramics are produced for dental usage: glass ceramics, glass infiltrated ceramics and polycrystalline ceramics.

Veneer ceramics are mainly feldspathic porcelains. They are composed almost entirely of an amorphous glass phase, ideal for optimal optical characteristics. Feldspathic ceramics usually provide mechanical resistance to compressive forces. However, they easily fracture under shear loads, due to their very low tensile strength [7].

Glass ceramics and glass-infiltrated ceramics consist of multi-phase materials.

Leucite-reinforced glass ceramics keep the esthetic performance with better mechanical properties. Few microns leucite crystals are embedded in a glass matrix, inside the Empress ceramic ingots. Pressed ceramics, like Empress, have been used successfully only for anterior crowns [7].

Lithium disilicate glass ceramics, veneered with fluoroapatite ceramics exhibit higher flexure strength [8]. Crystalline constituents (e.g. leucite crystallites in the glass ceramic Empress ${ }^{\circledR}$ II, A12O3-crystals in infiltrated ceramics etc.) are added to an amorphous glass phase [9]. The dispersion of ceramic crystals of high strength and elastic modulus within the glassy matrix can strengthen dental porcelain. As long as the glassy matrix has a thermal expansion similar to that of the crystals, both overall strength and elastic modulus may be increased [4].

"Glass-infiltrated high-strength core systems", with InCeran Alumina, followed by In-Ceram Spinnel and InCeram Zirconia offered a noticeable improvement in the mechanical properties of all-ceramic restorations. The loadbearing capacity and framework flexural strength are remarkably enhanced: the infiltrated glass fills the minute 
voids that might initiate cracks and induce excessive stress concentrations in the core structure $[6,10]$.

The two polycrystalline ceramics suitable for use in dentistry as framework materials are Alumina and Zirconia. They are able to withstand extensive stresses. They can provide sufficient mechanical properties besides the required esthetics [11].

The most common complication encountered with allceramic crowns was crown fracture [12]. All ceramic crowns made of lithium disilicate glass-ceramic resist to high fracture loads [13]. Adhesive cementation of crowns and bridges enhances the high survival rate of the all-ceramic material [5]. This reduces the critical stress situation and stabilizes the relatively fracture susceptible glass ceramics $[14,15]$.

Fracture toughness and Weibull modulus are other ceramic-specific parameters described in the literature. The Weibull modulus defines the distribution of strength values. A high Weibull modulus $(>10)$ reflects a close distribution and is therefore advantageous, especially if the strength is low. However, a high Weibull modulus should still be the goal even if there is high strength, for safety reasons [16].

Industrially produced ceramic blanks seem to be more structurally reliable for dental applications than ceramic materials which are manually processed under dental laboratory conditions [17]. Still, CAD/CAM procedures may induce surface and subsurface flaws $[18,19]$.

Alumina crowns combine the esthetic features to a longterm survival rate comparable to that of metal ceramic restorations [20]. The alumina crystals must remain intact during fritting if a significant reinforcing effect is to be obtained. The choice of particle size is a compromise between strength and esthetics [4]. Finer particles reduce translucency, and coarser particles reduce strength, probably because of the increased "notch effect" created at the grain boundaries of the crystals [4]. Aluminous porcelain is known to have poor tensile strength and fracture resistance, when subjected to shear forces [21]. The spaces between alumina crystals are occupied by a glassy matrix [4].

The In-Ceram system provides a zirconia-type coping system with 600 to $800 \mathrm{MPa}$ flexural strength and moderate translucency [22]. The type of In-Ceram alumina copings should be suitable for most locations [21,23].

Increasing strength and reliability of dental ceramic materials was driven by the growing demand for metal-free tooth-colored prostheses [24]. Y-TZP (Yttria partially stabilized tetragonal zirconia) was first introduced to dental clinics in the late 1990s. In most all-ceramic crowns, the prosthesis is composed of a zirconia core in the substructure, and a feldspathic porcelain in the superstructure. Zirconia material is now considered as the most suitable material for posterior restorations due to its higher bending, fracture strength $[25,26]$ and indentation fracture toughness [27] compared to other ceramics [28]. The yittria-tetragonal zirconia core with its stabilized tetragonal phase, is indicated in high stress sectors due to its ability to counteract crack propagation [29]. However, high incidence veneer chipping was a frequent reported technical complication [3, 30, 31]. In an earlier paper, the veneer-zirconia complications have been detailed [32]. Still, in brief, if bond failure has been pointed as chip- ping reason [29], differences in thermal coefficients [33], liner material and poor core wetting [34], veneer firing shrinkage [35, 36], phase transformation [37], loading stresses, flaw formation [38], coloring pigments [39] and surface properties [40] have been reported as potential causes. On the other hand, the possibility of fracture of the core, especially in the connector part, even rare, is potentially possible $[28,41]$. Worth noting that the flexural strength of the zirconia veneering porcelain is similar to metal-ceramics [41, 42]. When occlusal or palatal space is insufficient, the use of zirconia ceramic without veneering porcelain is not uncommon [43]. In these special clinical conditions, zirconia could be an antagonist to natural teeth or glass-ceramic restorations. The wear behavior of materials, as of tooth structure, is of clinical interest [44].

\section{ABRASION}

Type, microstructure, surface toughness and strength are some of the properties that will dictate the wear behavior of restorative materials $[44,45]$. Abrasion is defined as the property of one material to wear away another material by means of frictional contact [46]. Crystals in a glassy matrix form a non-homogenous material. So, wear will act by fracture rather than by plastic deformation as with metals. Poor relationship exists between ceramic hardness and enamel wear due to porcelain composition [47].

Tooth enamel, as well as ceramics, may be affected by environmental interactions. These factors have incidence on the mechanical behavior of the ceramic [47]. Dietary habits and dysfunctional occlusion can accelerate enamel loss [45].

The microstructure components of the ceramic will surely dictate its behavior [47]. In wet environment, the sodium ions loss to the aqueous milieu will reduce the ceramic surface hardness. At the microscopic level, the softened glass surface will easily stick to sharp asperities [48]. Adding that the presence of aqueous media will increase the coefficient of friction [49]. Studies show that the glassy matrix can be dissolved in the presence of extreme $\mathrm{pH}$ [50].

Feldspathic porcelain usually layers the metal framework. This ceramic has tendency for mechanical degradation, crack growth, and low fracture toughness. Porosities are included within this layer [51,52]. Aqueous environment might significantly reduce its strength [53]. Unexpected failure may result from this corrosion-fatigue mechanism. Feldspathic ceramic has fracture toughness similar to that of silicate glass, the most fatigue-susceptible ceramic. In this type of ceramics, the glass matrix and not the crystalline phase will largely control the mechanical properties [54].

Producing porcelain by mixing powder and liquid, will entrap air bubbles within the mass. Although vibration and vacuum-firing may reduce the porosity, it will not eliminate it completely. Pressing ceramic ingots, by eliminating mixing procedure, may minimize porosities. Some pores will remain associated with thermal differences during thermal processing. Porosity presence will reduce strength and esthetics. The stress is increased in the porous area leading to higher fracture probability. Particle size, viscosity of the matrix and firing temperature are also determining factors [54]. 
Shape of the pores is also affected by glass viscosity. Conventional feldspathic porcelain has lower viscosity than aluminous porcelain. The latter requires higher firing temperature to provide adequate wetting of the crystals. Irregular-shaped porosities that result from underfired aluminous porcelain are detrimental to porcelain strength [55].

Worth noting that low-fusing ceramic exhibits more porosities than the conventional one [56]. During wear process, when a subsurface porosity is exposed, this will result in sharp edges, which produce more wear of the antagonist [52, $57,58]$.

Wear to hardness is not a valid equation for materials that are brittle in nature. Wear will act by fracture and not by plastic deformation, as with metals, when ceramic slides against ceramic or enamel [54]. Crystals in a glass matrix form a non-homogeneous material. If we assist to plastic deformation of the glassy matrix under indentation loads before subsequent failure, crystalline materials are subject to dislocation mechanisms [59]. So porcelain composition may explain the poor relationship between ceramic hardness and enamel wear [54], despite the conclusions of Morrmann [19].

The fracture toughness determines the resistance of a material to rapid crack propagation [60]. Crystal size, aspect ratio and orientation, distribution of the glass phase, and porosities have a role in the determination of the fracture toughness of a material. Besides, chewing movements can generate tensile stresses [54].

When an applied load produces a stress at the tip of a flaw or crack equal to the intrinsic strength of the vitreous matrix, fracture of a material starts [61]. Ceramic failure may occur without any perceptible plastic deformation. Wear process will start with crack formation; then subsequent crack will grow over time, followed by surface chipping or catastrophic material fracture, perpendicular to the applied tensile forces [60]. Defects such as thermal microcracks, residual scratches, and large grains will act as stress concentrators increasing the probability of crack propagation under loading. Brittle ceramic will fracture adjacent to these flaws [62]. Albashaireh concluded that ceramic is more sensitive to fatigue due to material intrinsic imperfections than to attrition wear [44].

Radial cracking in the core beneath the contact area was the dominant fracture mode reported in the full-ceramic crowns. Off-axis loading induced debonding near the shoulder of the crown, under substantially lower occlusal loads compared to those required for crack initiation [63]. Crowns veneered with lithium disilicate ceramic displayed less failure than feldspathic porcelain [17].

Dental clinicians should also be conscious of the wear effect of dental restorations on the opposing teeth or restorations. As mentioned before, the wear behavior of human enamel and feldspathic porcelain varies according to the type of substrate materials. Enamel wear is a progressive phenomenon associated with physical, microstructural, chemical, and surface characteristics of opposing dental ceramics [64]. Despite their good aesthetic features and biocompatibility $[43,65]$, many studies showed that the ceramic destroys the enamel [66].
Surface roughness has incidence on the abrasiveness of the material itself and the opposing dentition [28]. Studies agree that unpolished ceramics could be particularly harmful to opposing natural teeth. A metal occlusal surface, and preferably one of high noble content, is chosen to minimize wear of the natural dentition [67]. Gold alloys are reported to wear at approximately the same rate as enamel, function on the type of alloy used [68-70]. Long history of clinical use gave them the reputation to be "kind" to antagonist tooth structure and restorations [71]. Mechanically stiffer, nickel-chromium alloys showed a lower wear rate. Being more difficult to adjust and polish, they induce more wear than gold to the opposing teeth [72]. Although also wear resistant, the chrome-cobalt is less abrasive to enamel than a soft gold alloy [51, 70]. With its minimal wear of opposing enamel, among all restorative materials, the type III gold alloy remains ideal [28].

As demonstrated by several researchers, ceramic substrates induce greater abrasive wear of dental enamel compared to dental alloys [73]. Despite manufacturers' claim of the veneer ceramic enamel-like tribological qualities (friction, lubrication, and wear interaction surface), the wear mechanism remains unclear and heterogenic results reported [64]. However, Esquivel et al noticed that equivalent wear occurs between ceramic/enamel and enamel/enamel pairs [74].

Low-fusing ceramics are reported to be less abrasive to enamel but wear more than feldspathic types [75]. Cast and pressed glass ceramics also appear to be less abrasive [76]. A machined ceramic is reported to be the least enamel abrasive and the most wear resistant among several types of ceramics evaluated [77]. Ceramic microstructure, surface roughness, and oral environment influence antagonist tooth wear process [51].

Nowadays, rehabilitating occlusion by restoring upper and lower is frequent. Ceramic against ceramic may produce severe attrition under high occlusal forces, and acceptable wear levels under lower occlusal forces, as reported with removable prostheses [44].

When opposing metal-ceramic crowns, porcelain and gold showed equal wear values. The porcelain wear mechanism is clearly a fatigue type, whereas it is a combination of fatigue and abrasion in the case of gold restorations. A microfilled resin, proposed as shock absorber, showed three to four times wear rates higher than porcelain [69]. Material loss occurred, within a very short period of time, when composites and especially unfilled polymers are used [78].

A method to bond indirect composite material to zirconia was also proposed [79]. Composite plastic and visco-elastic effects, added to its susceptibility to creep and recovery, gave some functional advantages, especially in high occlusal stress areas $[80,81]$. The force, contact area and duration were reported greater for molar chewing cycles than incisor ones [82].

Shading materials are essentially metal oxide particles. Wear of a ceramic material may be increased as metal oxides are abrasive to enamel. Glassy phase being less wearresistant, wears preferentially. This will expose the highly abrasive staining particles [78]. A glazed surface is believed 
to reduce the wear of antagonist teeth. However, this glaze layer is lost after a short period in function, or by occlusal adjustments at chairside [44, 64]. If not adequately polished, the underlying surface, when exposed, may accelerate abrasive wear of opposing teeth. Unpolished ceramics can cause substantial wear and be detrimental to opposing natural teeth $[51,83]$. CAD/CAM restorations are polished to eliminate surface defects caused by machining [19]. This will establish high gloss and low roughness on the external surfaces. Results showed that a significantly higher surface gloss results from machine polishing compared to intra-oral manual polishing [84]. Intra-oral polishing is sometimes needed after post-cementing occlusal adjustments [85]. Intra-oral zirconia polishing to a degree which does not forward excessive wear of the opposite dentition, still has to be proved [19].

\section{ZIRCONIA RESTORATIONS BEHAVIOR}

Feldspathic ceramic is usually used for zirconia veneering with chipping complication reported. Studies showed that $\mathrm{CAD} / \mathrm{CAM}$ veneers reduce material fatigue failure [17]. When occlusal or palatal space is insufficient, the use of zirconia ceramic without veneering might be a solution, especially when using resin-bonded fixed dental prostheses [66]. Laboratories proposed this method to avoid chipping [44]. By improving the esthetic of zirconia, a more solid framework could be constructed with a conservative preparation similar to full-cast metal preparation [64]. Zirconia specimens showed considerably lower vertical and volumetric loss than other ceramics. Still, its behavior as an antagonistic material would be of interest clinically [44], the hardness of zirconia being emphasized [28]. It has been demonstrated that The YTZ-ceramic expressed extremely high wear resistance against enamel [64]. No material wear could be detected $[19,64]$.

Should the dentist be aware of the wear of antagonist dentition when opposed to zirconia?

Although zirconia is a hard material, soft antagonists such as polyethylene rarely wear on zirconia. This was the result of two types wear test (unidirectional rotary motion and reciprocating motion) in different types of lubricant. YPSZ ceramic remains a low friction biomaterial due to its wear-resistant properties and high strength [86]. Tests on a chewing simulator reported less antagonist wear than for porcelain [87]; still, more than type IV gold [88], composite resins (MZ100 and Z100) and leucite-containing glass (Empress) on a premolar enamel [89].

Using dual-axis mastication simulator, Albashaireh et al. proposed zirconia as a more beneficial material in terms of antagonistic tooth wear [90].

With the Oregon Health \& Science University (OHSU) oral wear simulator, Sorensen et al. confirmed that the polished Lava showed small enamel loss similar to that of gold alloy (Aquarius), lower than Omega 900, Empress, and Empress 2 [91]. Adding that the polished zirconia was less abrasive to enamel than the glazed zirconia, Ceramco porcelain, and Cerec Mark II [92].

Kim [28] and Mormann noticed that zirconia induced low wear of the enamel antagonist compared to feldspathic ceramic [19]. Using a chewing simulator, Stawarczyk et al. confirmed that the polished zirconia showed a lower wear rate compared to $\mathrm{CoCr}$ (Denta NEM, CoCr alloy) [93].

Surface of a fullcontour zirconia restoration could be subjected to numerous surface treatments, such as grinding, polishing, glazing, and heat. Little data is available about its incidence on antagonist wear. Using the University of Alabama wear-testing device, Yang et al. [94] argued that the surface character of Y-TZP (polished, stained, or stained then glazed) is a relatively homogeneous surface. The processed zirconia was reported more abrasive than the polished one [88].

If Shar et al. [95], by using a modified Leinfelder wear testing machine, noticed larger enamel loss of a premolar caused by polished than the glazed one, Jung found the mirror-polished zirconia significantly less abrasive than the glazed and porcelain-veneered ones [96]. This was confirmed by Stawarczyk within three types of surface-treated zirconia (ZENOTEC Zr Bridge Translucent) [93]. Kuretzky et al. used a longitudinal moving notch device to demonstrate that the polished zirconia showed the least wear when abraded with a steatite sphere, compared to four kinds of surface-treated zirconia (rough, polished, glazed, and veneered Lava) and e.max CAD [97].

Basunbul pointed that the glazed zirconia lost its glazed layer, whereas the polished zirconia kept an unchanged surface [92]. Yang added that the Zirkonzahn Y-TZP without glazing was less abrasive than Y-TZP with staining and glazing [94].

To reduce the wear of the opposing enamel, Mitov advise that if occlusal adjustments with coarse diamonds are performed, surface must be well-polished [64].

In 2013 , Kontos et al., by using a chewing simulator, reported that the lowest wear on the antagonist was induced by the polished zirconia compared to sandblasted, ground, and glazed zirconia [98]. In the same year, Janyavula et al. [99] concluded that the highly polished zirconia is preferable to the glazed zirconia.

Still, Little quantitative and qualitative data are available on the wear resistance of ceramic materials opposing zirconia ceramic antagonists $[44,78]$.

Conclusions about the zirconia behavior can be deduced from three recent publications.

One clinical review gave emphasis on specific challenges associated with full-contour zirconia ceramics. A set of unique challenges stemming from shade production, tribological behavior, and long-term chemical stability is raised by use of this material. Intricate complexities in mechanical and chemical behavior of partially stabilized zirconia have not yet been fully explored. To achieve expected mechanical and chemical properties, each step of the fabrication process of zirconia ceramics must be cautiously controlled. This includes blank fabrication, green machining, sintering process, and surface treatments, whether chemical, thermal, or mechanical [100].

Two systematic reviews aimed to assess the zirconia properties [101, 102]. The authors noticed that the polishing will remove all surface residual stresses, and eliminate superficial flaws and cracks on the material surface [101]. The 
polished zirconia specimens showed a favorable wear behavior opposing natural teeth. Enamel pathological wear opposing zirconia full-coverage restorations has not yet been confirmed. The variation in enamel specimen preparation, and the morphological and structural differences of natural enamel, can explain the disparity in the collected wear data among the studies.

It is important to assess the enamel wear behavior opposing zirconia using clinically relevant surface contours as well as to investigate the long-term stability and abrasiveness of polished zirconia. The zirconia corrosive wear has not yet been considered [102].

It is also confirmed that polished zirconia shows less wear loss than porcelain-veneered zirconia. Porcelain is composed of a feldspathic glass and leucite crystal grains. Wear such as mastication, will easily make the glass disappears. Consequently, the exposed large leucite grains act as abrasive materials. Whereas, Zirconia has a fine and homogeneous microstructure [87].

\section{MECHANICAL BEHAVIOR UNDER EXTREME CONDITIONS}

From the clinical point of view, it is not the initial strength of the ceramic material itself that is of prime importance, but the time that the permanent restoration will last.

According to ISO 6872, the minimum toughness values for substructure ceramic for non adhesively cemented anterior or posterior crowns and three unit substructure ceramic not involving molars should be $3 \mathrm{MPa} / \mathrm{m}$; three-unit substructure ceramic involving molars, $3.5 \mathrm{MPa} / \mathrm{m}$; and substructure ceramic involving four or more units, $5 \mathrm{MPa} / \mathrm{m}$ [103].

For posterior applications, an initial strength of approximately $1000 \mathrm{~N}$ is also required to guarantee successful longterm restorations. This may be required for the material to withstand fatigue with a prospective safety margin [104]. If we consider the maximal forces of $400 \mathrm{~N}$ in the oral anterior area and $600 \mathrm{~N}$ in the oral posterior area, only zirconia can provide the initial strength needed to insert multi-unit bridges [105]. Zirconia can withstand many times the load level occurring in the mouth (loads measured for bruxism even up to 800 N) [106-108].

Yip described different patient factors that may increase tooth and restoration wear. He mentioned heavy biting forces and parafunctional habits, incorrect toothbrushing/dentifrices, abrasive and acidic diets, regurgitation, reduced salivary flow and altered composition, defective tooth structure, and reduced posterior tooth support [51].

Kinsel reported that, among patients, who showed the common clinically observable occlusal wear patterns, declared bruxers presented $60 \%$ rate of major porcelain fractures, and $67 \%$ rate of minor fractures [109].

Under extreme conditions, no material will last long. Only small differences in wear resistance of gold and ceramic materials were reported. However, metal or metalceramic restorations seem to be the safest choice in cases of high load conditions [110]. Gold-acrylic FDPs have been proposed for heavy bruxers to reduce the risk of chipping, although resin-based materials wear rate was three to four times more than gold or ceramics wear rate [111].

On the other hand, not surprisingly, the choice of crown material has a great influence on the maximum principal stress in the crown. Increasing the stiffness of the crown material concentrates more of the stress within the crown, whereas crowns fabricated from lower stiffness materials transfer more stress to the cement layer and tooth supporting core [112]. Maximum principal stress within the crown may be sensitive to different factors for different material systems. Material thickness, cement modulus, load position, and supporting tooth core are important contributors [112].

Zirconia core material show higher strength than other all-ceram materials, comparable to conventional metal frameworks. Even a good longevity has been demonstrated for posterior regions, where force, contact area and duration were greater, framework fractures were reported related to occlusal trauma $[18,113,114]$. Compared to metal-ceramic restorations, lower loads accumulation initiated porcelain veneer damage and failure in the case of zirconia [3].

In the connector area, concentration of heavy stresses increases the risk of catastrophic fracture. Therefore, evaluating prospective abutments is mandatory with emphasis on abutment mobility. The use of all-ceramic FPDs with a cantilever design remains questionable. The pontic acts as a lever depressed under occlusal forces. Finally, in the case of heavy bruxers, uncontrolled severe parafunctional activity may be a major contraindication for all-ceramic FPDs [115].

In case of confirmed bruxism, splinting must be avoided [67]. Restorations should be limited to single crowns whenever possible; physiological tooth mobility will be unrestrained. Cementation and crown failure will be more easily detected and corrected [111].

\section{DISCUSSION}

This paper tried to overview the prosthetic materials commonly used and their implication in the wear process of antagonist teeth or prostheses. Comparison of the protocols remains difficult due to the differences in the methodology. Studies investigated frictional wear, that is, masticatory attrition, as well as abrasion by tooth brushing. Methodically, attrition is defined as the physiological wearing away of the tooth structure as a result of tooth-to-tooth contact, as in mastication, without (two-body wear) or with abrasive substance (three-body wear) intervention $[116,117]$.

Wear is normally a slow process [118]. The clinical manifestation of attrition shows the appearance of a flat circumscribed facet on enamel and/or on restorative material. As the lesion progresses, there is a tendency towards the reduction of the cusp height and flattening of the occlusal inclined planes. That may lead to loss of vertical dimension [117].

How well this phenomenon can be imitated experimentally, with the help of artificial masticators to assess the adequacy of restorative materials, still remains a matter of discussion $[119,120]$.

Variable study conditions and plethora of materials available made the comparison of the results from relevant litera- 
ture, a challenging issue [121]. Usually, a failure in any clinical trial results from a combination of causes or events [122]. Some of the studies lack scientific support [123, 124]. Reproducing intra-oral conditions, during the in vitro studies, is quite difficult. An effort was made to create artificial oral environments by applying cyclic forces in artificial saliva, under fluctuating temperature [125]. Results were then extrapolated to intraoral conditions. Long-term clinical studies are still needed to demonstrate the true outcome $[67,126]$ and make conclusions [121]. In the era of evidence-based dentistry, reinforcing standardization of clinical cohort studies will permit more efficient conclusions [114]. It has been noted that some granted research centers may be reluctant to publish adverse results [127].

Describing restoration materials and evaluating survival rates were not the aim of this review. Factors related to restorations wear and abrasiveness, were emphasized. Many restorations may continue to provide satisfactory service, despite minor chipping. "Replace for preventive reasons" recommendation can often be omitted [51].

Some dogma has blamed hardness for the accelerated loss of material. Large variation of measurement values and conditions lowered the reliability of clinical reports. Strong correlation between ceramic hardness and enamel wear rates has not been confirmed by scientific studies [128]. Ceramic microstructure, roughness of contacting surfaces, and environmental influences are directly involved [54]. Internal porosities and surface defects increase wear by acting as stress concentrators. Glazing is quickly lost under function. Underlying polished surface is mandatory. Internal characterization of ceramics is preferred to avoid abrasive metal oxides present in shading materials [54].

The homogeneity and particle size of the microstructure of the restorative material has a strong incidence of the wear process. The zirconia fine uniform structure allows a mirror polishing, by using appropriate polishing materials and fine diamond particles instruments. No added enamel wear was generated by antagonist zirconia restoratives. However, ground surface roughness of zirconia increased the wear of antagonist enamel. Therefore, their surface should be sufficiently mirror-polished after occlusal adjustments. Furthermore, glazing as a finishing surface of zirconia is not recommended [94].

Acidic and/or alkalic chemical attack, in a wet oral environment, will affect ceramic surfaces. Well controlled patient dietary habits and systematic problems will help to maintain a neutral $\mathrm{pH}$ [54]. Incorrect toothbrushing/dentifrices could also be harmful [83] and patient education is required [51].

The review mentioned the effects of bruxism on various kinds of prosthetic restorations. There is no evidence that prosthetic therapy, or any other available treatment, can eliminate bruxism. Equally, there is no evidence that bruxism can be caused by prosthetic therapy. The need for research in this area remains clearly great [83].

Dysfunctional occlusion or parafunctional habits such as clenching and bruxism can be triggered by a degraded ceramic surface. This may accelerate the wear process. When occlusal forces exceed tensile strength limits of the veneering porcelain, a fracture may occur [21]. Ceramic surface alteration and the opposing enamel should be controlled and polished on a regular basis [54].

In case of extreme bruxism, excessive occlusal parafunctional forces may lead to posterior core fail [21]. Severe wear is an indication for night guard recommendation. Doctors cannot control patient inherent factors [54].

Heavy biting forces necessitate the placement of metal or metal-ceramic restorations [51]. Lack of a sound standard and wear incidence on the opposing teeth, limit the use of monolithic zirconia crowns [28]. The material's hardness is obviously no predictive factor neither for material nor for the antagonist wear [78].

A well distributed occlusion has an important effect on the wear process [54]. Sailer demonstrated that crack propagation direction originated from a roughness of the ceramic at the occlusal region of the cusp [129]. Multiple contact areas (rather than a single point of contact) lower stress concentrations. This may help to protect the stability of the occlusion. Wear process requires sliding of antagonist surfaces. Therefore minimizing sliding contacts in centric and eccentric movements is essential when placing new ceramic restorations [54].

\section{CONCLUSION}

No current material can fulfill all of the requirements of an ideal restorative material, considering esthetic, mechanical and economic demands. Material as well as patient factors have been implemented. Several factors have been raised.

Patient selection and controlling wear factors are essential. Careful tooth preparation, adequate core support of veneering porcelain, proper occlusal adjustment, and careful cementation technique will enhance success and longevity rates.

Ceramic material has been shown to destroy enamel, whereas Gold is reported to be kind to antagonist. Machined ceramic is the less abrasive than condensable one.

Lack of a sound standard and wear incidence on the opposing teeth, limit the use of monolithic zirconia crowns. Available data shows low enamel wear when opposed to zirconia. The zirconia fine uniform structure allows a mirror polishing. Concerns remain regarding the structural stability of zirconium dioxide ceramics when exposed to the oral environment. Compared to metal-ceramic restorations, lower loads accumulation initiated porcelain veneer damage and failure in the case of zirconia.

\section{CONFLICT OF INTEREST}

The author confirms that this article content has no conflict of interest.

\section{ACKNOWLEDGEMENTS}

Declared none.

\section{REFERENCES}

[1] Donovan TE. Porcelain-fused-to-metal (PFM) alternatives. J Esthet Restor Dent 2009; 21: 4-6. 
[2] Napankangas R, Raustia A. Twenty-year follow-up of metalceramic single crowns: a retrospective study. Int J Prosthodont 2008; 21: 307-11.

[3] Silva NRFA, Bonefante EA, Zavanelli RA, Thompson VP, Ferencz JL, Coelho GP. Reliability of Metalloceramic and Zirconia-based Ceramic Crowns. J Dent Res 2010; 89(10): 1051-6.

[4] McLean JW. Evolution of dental ceramics in the twentieth century. J Prosthet Dent 2001; 85: 61-6.

[5] Addison Owen, Maquis PM, Fleming Garry JP. Resin strengthening of dental ceramics- The impact of surface texture and silane. J Dent 2007; 35416-24.

[6] Zarone F, Russo S, Sorrentino R. From porcelain-fused-to-metal to zirconia: Clinical and experimental considerations. Dent Mater 2011; 27: 83-96.

[7] Raigrodski A, Chiche GJ. The safety and efficacy of anterior ceramic fixed partial dentures: a review of the literature. J Prosthet Dent 2001; 86: 520-5.

[8] Chen YM, Smales R, Yip KH, Sung WJ. Translucency and biaxial flexural strength of four ceramic core materials. Dent Mater 2008; 24: $1506-11$.

[9] Holand W, Ritzberger V, Appel C, et al. Future perspectives of biomaterials for dental restoration. J Eur Ceramic Soc 2009; 29: 1291-7.

[10] Xiao-Ping L, Jie-Mo T, Yung-Long Z, Ling W. Strength and fracture toughness of MgO-modified glass infiltrated alumina for CAD/CAM. Dent Mater 2002; 1(8): 216-20.

[11] Gemalmaz D, Ergin S. Clinical evaluation of all-ceramic crowns. J Prosthet Dent 2002; 87: 189-96.

[12] Goodacre CJ, Bernal G, Rungcharassaeng K, Kan JYK. Clinical complications in fixed prosthodontics. J Prosthet Dent 2003; 90: 31-41.

[13] Albrecht T, Kirsten A, Kapperta HF, Fischerb H. Fracture load of different crown systems on zirconia implant abutments. Dent Mater 2 011;27: 298-303.

[14] Pauli C. Flexural strength of 3-unit PFM and all ceramic maxillar posterior bridges. ZWR 1996; 105(11): $526 \mathrm{ff}$.

[15] Al-Wahadni Ahed M, Husey DL, Grey Nicholas, Hatamleh Muhanad M. Fracture resistance of Aluminium Oxide and lithium disilicate -based crowns using different luting cements: An in-vitro study. J Contempor Dent Pract 2009; 10(2): 1-10.

[16] Klein CA. Characteristic strength, Weibull modulus, and failure probability of fused silica glass. Optic Engine 2009; 48(11): 113401.

[17] Schmitter M, Mueller M, Rues S. Chipping behaviour of allceramic crowns with zirconia framework and CAD/CAM manufactured veneer. J Dent 2012; 40: 154-62.

[18] Tinschert J, Natt G, Mautsch W, Augthun M, Spiekermann H. Fracture resistance of lithium disilicate-, alumina-, and zirconiabased three-unit fixed partial dentures: a laboratory study. Int $\mathbf{J}$ Prosthodont 2001; 14: 231-8.

[19] Morrmann WH, Stawarczyk B, Ender A, Sener B, Attin T, Mehl A. Wear characteristics of current aesthetic dental restorative CAD/CAM materials: Two-body wear, gloss retention, roughness and Martens hardness J Mechan Behav Biomed Mater 2013; 20: 113-25.

[20] Galindo ML, Sendi P, Marinello CP. Estimating long-term survival of densely sintered alumina crowns: A cohort study over 10 years. J Prosthet Dent 2011; 106: 23-8.

[21] Segal BS. Retrospective assessment of 546 all-ceramic anterior and posterior crowns in a general practice. J Prosthet Dent 2001; 85 544-50.

[22] McLaren EA, White S, Glass-infiltrated zirconia/alumina-based ceramic for crowns and fixed partial dentaures. Prac Periodont Aesthet Dent 1999; 11: 985-94; quiz 996.

[23] Yoshinari M, Derand T. Fracture strength of all-ceramic crowns. Int J Prosthodont 1994; 7: 329-38.

[24] Raigrodski AJ. Materials for all-ceramic restorations. J Esthet Restor Dent 2006; 18: 117-8.

[25] Manicone PF, Rossi IP, Raffaelli L. An overview of zirconia ceramics: basic properties and clinical applications. J Dent 2007; 35: 819-26.

[26] Yang B, Lang.-Jansen H, Scharnberg M, et al. Influence of saliva contamination on zirconia ceramic bonding. Dent Mater 2008; 24: 508-13.

[27] Yilmaz H, Aydin C, Gul BE. Flexural strength anf fracture toughness of dental core ceramics. J Prosthet Dent 2007; 98: 120-8.
[28] Kim M-J, Oh S-H, Kim J-H, et al. Wear evaluation of the human enamel opposing different Y-TZP dental ceramics and other porcelains. J Dent 2012; 40: 979-88.

[29] Studart A, Filser F, Kocher P, Luthy H, Gauckler LJ. Mechanical and fracture behavior of veneer-framework composites for allceramic dental bridges. Dent Mater 2007; 23: 115-23.

[30] Raigrodski AJ, Chiche G, Potiket N. The efficacy of posterior three-unit zirconium-oxide-based ceramic fixed partial dental prostheses: a prospective clinical pilot study. J Prosthet Dent 2006; 96: 237-44.

[31] Sailer I, Feher A, Filser F, Gauckler LJ, Luthy H, Hammerle CH. Five-year clinical results of zirconia frameworks for posterior fixed partial dentures. Int J Prosthodont 2007; 20: 383-8.

[32] Daou EE. The zirconia ceramic: strengths and weaknesses. Open Dent J 2014; 8: 33-42.

[33] Aboushelib MN, Feilzer A, de Jager N, Kleverlaan CJ. Prestresses in bilayered allceramic restorations. J Biomed Mater Res B Appl Biomater 2008; 87: 139-45.

[34] Aboushelib MN, Kleverlaan C, Feilzer AJ. Microtensile bond strength of different components of core veneered all-ceramic restorations. Part II: zirconia veneering ceramics. Dent Mater 2006; 22: 857-63.

[35] Fischer J, Stawarczyk B, Tomic M, Strub JR, Hammerle CHF. Effects of thermal misfit between different veneering ceramics and zirconia frameworks on in vitro fracture load of single crowns. Dent Mater 2007; 26(6): 766-72.

[36] Fischer J, Grohmann P, Stawarczyk B. Effect of zirconia surface treatments on the shear strength of zirconia/veneering ceramic composites. Dent Mater J 2008; 27: 448-54.

[37] de Kler M, de Jager N, Meegdes M, van der Zel JM. Influence of thermal expansion mismatch and fatigue loading on phase changes in porcelain veneered Y-TZP zirconia discs. J Oral Rehabil 2007; 34: 841-7.

[38] Wang H, Aboushelib M, Feilzer AJ. Strength influencing variables on CAD/CAM zirconia frameworks. Dent Mater 2008; 24: 633-8.

[39] Aboushelib MN, Kleverlaan CJ, Feilzer AJ. Effect of zirconia type on its bond strength with different veneer ceramics. J Prosthodont 2008; 17: 401-8.

[40] Rahaman MN, Li Y, Bal BS, Huang W. Functionally graded bioactive glass coating on magnesia partially stabilized zirconia (Mg-PSZ) for enhanced biocompatibility. J Mater Sci Mater Med 2008; 19: 2325-33.

[41] Stawarczyk B, Özcan M, Roos M, Trottmann I, Sailer I, Hämmerle CHF. Load-bearing capacity and failure types of anterior zirconiacrowns veneered with overpressing and layering techniques. Dental Mater 2011; 27: 1045-53.

[42] Aboushelib MN, de Jager N, Kleverlaan CJ, et al. Microtensile bond strength of different components of core veneered all-ceramic restorations. Dent Mater 2005; 21: 984-91.

[43] Kern M. Clinical long-term survival of two-retainer and singleretainer all-ceramic resin-bonded fixed partial dentures. Quintessence Int 2005; 36: 141-7.

[44] Albashaireh ZSM, Ghazal M, Kern M. Two-body wear of different ceramic materials opposed to zirconia ceramic. J Prosthet Dent 2010; 104: 105-13.

[45] Heintze S, Cavalleri A, Forjanica M, Zellwegera G, Roussonb V. Wear of ceramic and antagonist-A systematic evaluation of influencing factors in vitro. Dent Mater 2008; 24: 433-49.

[46] The Academy of Prosthodontics. Glossary of prosthodontic terms. 7th ed. J Prosthet Dent 1999; 81(1): 39-110.

[47] Oh WS, Annusavice K, Effect of connector design on the fracture resistance of all-ceramic fixed partial dentures. J Prosthet Dent 2002; 87: 536-42.

[48] Kaidonis JA, Towsend G, Tansley GD. Wear of human enamel: a quantitative in vitro assessment. J Den Res 1998; 771983-90.

[49] Callister WD Jr. Materials science and engineering: an introduction. John Wiley \& Sons: New York. 1997, pp. 179-95.

[50] Larsen MJ. Chemical events during tooth dissolution. J Den Res 1990; 69: 575-80; discussion 634-6.

[51] Yip KHK, Smales RJ, Kaidonis JA. Differential wear of teeth and restorative materials: Clinical implications. Int J Prosthodont 2004; 17: 350-6.

[52] Kelly JR, Campbell S, Bowen HK. Fracture-surface analysis of dental ceramics. J Prosthet Dent 1989; 62: 536-41. 
[53] Morena R, Beaudreau G, Lockwood PE, Evans AL, Fairhurst CW. Fatigue of dental ceramics in a simulated oral environment. J Dent Res 1986; 65: 993-7.

[54] Oh W-S, Delong R, Anusavice KJ. Factors affecting enamel and ceramic wear: A literature review. J Prosthet Dent 2002; 87: 451-9.

[55] Piddock V. Effect of alumina concentration on the thermal diffusivity of dental porcelain. J Dent 1989; 17: 290-4.

[56] Magne P, Oh W, Pintado MR, DeLong R. Wear of enamel and veneering ceramics after laboratory and chairside finishing procedures. J Prosthet Dent 1999; 82: 669-79.

[57] DeLong R, Douglas W, Sakaguchi RL, Pintado MR. The wear of dental porcelain in an artificial mouth. Dent Mater 1986; 2: 214-9.

[58] Jacobi R, Shillinbury HJ, Duncanson MG Jr. A comparison of the abrasiveness of six ceramic surfaces and gold. J Prosthet Dent 1991; 66: 303-9.

[59] Seghi RR, Rosenstiel S, Bauer P. Abrasion of human enamel by different dental ceramics in vitro. J Dent Res 1991; 70: 221-5.

[60] Mecholsky JJ. Fracture mechanics principles. Dent Mater 1995; 11: 111-2.

[61] Ekfeldt A, Fransson B, Soderlund B, Oilo G. Wear resistance of some prosthodontic materials in vivo. Acta Odontol Scand 1993; 51: 99-107.

[62] Callister WD Jr. Materials science and engineering: an introduction. John Wiley \& Sons: New York. 1997; pp. 179-95.

[63] Zhang D, Lu C, Zhang X, Mao S, Arola D. Contact fracture of fullceramic crowns subjected to occlusal loads. J Biomechanics 2008; 41: 2995-3001.

[64] Mitov G, Heintz SD, Walz S, Woll K, Muecklichd F, Pospiecha P. Wear behavior of dental Y-TZP ceramic against natural enamel after different finishing procedures. Dent Mater 2012; 28: 909-18.

[65] Taskonak B, Borges G, Mecholsky JJ Jr, Anusavice KJ, Moore BK, Yan J. The effects of viscoelastic parameters on residual stress development in a zirconia/glass bilayer dental ceramic. Dent Mater 2008; 24: 1149-55.

[66] Ghazal M, Kern M. The influence of antagonistic surface roughness on the wear of human enamel and nanofilled composite resin artificial teeth. J Prosthet Dent 2009; 101: 342-9.

[67] Johansson A, Omar R, Carlsson GE. Bruxism and prosthetic treatment: A critical review. J Prosthodont Res 2011; 55: 127-36.

[68] Ramp MH, Suzuki S, Cox CF, Lacefield WR, Koth DL. Evaluation of wear: Enamel opposing three ceramic materials and a gold alloy. J Prosthet Dent 1997; 77: 523-30

[69] Ekfeldt A, Olio G. Wear of prosthodontic materials: an in vivo study. J Oral Rehab 1990; 17: 117-29.

[70] Graf A, Johnson G, Mehl A, Rammelsberg P. The influence of dental alloys on three-body wear of human enamel and dentin in an inlay-like situation. Oper Dent 2002; 27: 167-74.

[71] Hickel R, Manhart J. Longevity of restorations in posterior teeth and reasons for failure. J Adhes Dent 2001; 3: 45-64.

[72] O'Sullivan ET, Setchell D. Two-body method for testing tooth wear by restorative materials [abstract 484]. J Dent Res 1998; 77: 692.

[73] Metzler KT, Woody R, Miller AW 3rd, Miller BH. In vitro investigation of the wear of human enamel by dental porcelain. $\mathrm{J}$ Prosthet Dent 1999; 81: 356-64.

[74] Esquivel-Upshawa JF, Rose JW, Barrett AA, et al. Three years in vivo wear: Core-ceramic, veneers, and enamel antagonists. Dent Mater 2012; 28: 615-21

[75] Derand P, Vereby P. Wear of low-fusing dental porcelains. J Prosthet Dent 1999; 81: 460-3.

[76] Ratledge DK, Smith B, Wilson RF. The effect of restorative materials on the wear of human enamel. J Prosthet Dent 1994; 72: 194-203.

[77] Al-Hiyasat AS, Saunders W, Smith GM. Three-body wear associated with three ceramics and enamel. J Prosthet Dent 1999; 82: 476-81.

[78] Heintze SD, Cavalleri A, Forjanica M, Zellwegera G, Roussonb V. Wear of ceramic and antagonist: A systematic evaluation of influencing factors in vitro. Dent Mater 2008; 24: 433-49.

[79] Hatta M, Shnya A, Yokoyama D, Gomi H, Vallittu PK. The effect of surface treatment on bond strength of layering porcelain and hybrid composite bonded to zirconium dioxide ceramics. J Prosthodont Res 2011; 55: 146-53.

[80] Vaidyanathan J, Vaidyanathan T. Flexural creep deformation and recovery in dental composites. J Dent 2001; 29: 545-51.
[81] Komine F, Strub J, Matsumura H. Bonding between layering materials and zirconia frameworks. Jap Dent Sci Rev 2012; 48: 153-61.

[82] Kohyama K, Hatakeyama E, Sasaki E, Azuma T, Karita K. Effect of sample thickness on bite force studied with a multiple-point sheet sensor. J Oral Rehabil 2004; 31: 327-34.

[83] Johansson A, Omar R, Carlsson GE. Bruxism and prosthetic treatment: A critical review. J Prosthodont Res 2011; 55: 127-36.

[84] Heintze SD, Gorjanic M, Rousson V. Surface roughness and gloss of dental materials as a function of force and polishing time in vitro. Dent Mater 2006; 22: 146-65.

[85] Stawarczyk B, Ozcan M, Schmutz F, Trottmann A, Roos M, Hammerle CHF. Two-body wear of monolithic, veneered and glazed zirconia and their corresponding enamel antagonists. Acta Odontol Scand 2013; 71: 102-12.

[86] Kumar P, Oka M, Ikeuchi K, et al. Low wear rate of UHMWPE against zirconia ceramic (Y-PSZ) in comparison to alumina ceramic and SUS 316L alloy. J Biomed Mater Res 1991; 25: 81328

[87] Preis V, Behr M, Kolbeck C, Hahnel S, Handel G, Rosentritt M. Wear performance of substructure ceramics and veneering porcelains. Dent Mater 2011; 27: 796-804.

[88] Tambra TR, Razzog M, Lang BR, Wang R-F, Lang BE. Wear of enamel opposing YPSZ zirconia core material with two surface finish. In: 32 ${ }^{\text {nd }}$ AADR; [Abstr. No. 0915] 2003.

[89] Culver S, Cakir D, Burgess J, Ramp L. Wear of the enamel antagonist and five restorative materials. . In: $37^{\text {th }}$ AADR; [Abstr. No. 0367] 2008

[90] Albashaireh ZSM, Ghazal M, Kern M. Two-body wear of different ceramic materials opposed to zirconia ceramic. J Prosthet Dent 2010; 104: 105-13.

[91] Sorensen JA, Sultan E, Sorensen PN. Three-body wear of ename against full crown ceramics. In: $89^{\text {th }}$ IADR; [Abstr. No. 1652] 2011.

[92] Basunbul G, Nathanson D. Human enamel wear against four dental ceramics in vitro. In: 89 ${ }^{\text {th }}$ IADR; [Abstr. No. 1650]. 2011.

[93] Stawarczyk B, Ozcan M, Scmutz F, Trottmann A, Roos M, Ha"mmerle F. Two-body wear of monolithic, veneered and glazed zirconia and their corresponding enamel antagonists. Acta Odontol Scand 2013; 71: 102-12

[94] Yang DH, Park J, Yang HS, et al. Antagonist enamel wear to 3 CAD/CAM full contour zirconia ceramics. In: $90^{\text {th }}$ IADR; [Abstr. No. 1381]. 2012

[95] Shar S, Mickelson C, Beck P, Lamp LC, Cakir D, Burgess J. Wear of enamel on polished and glazed zirconia. In: $39^{\text {th }}$ AADR; [Abstr. No. 227]. 2010.

[96] Jung Y-S, Lee J-W, Choi Y-J, Ahn J-S, Shin S-W, Huh J-B. A study on the in-vitro wear of the natural tooth structure by opposing zirconia or dental porcelain. J Adv Prosthodont 2010; 2: 1111-5.

[97] Kuretzky T, Urban M, Dittmann R, Peez R, Mecher E. Wear behaviour of zirconia compared to state-of-the-art ceramics. In: $89^{\text {th }}$ IADR; [Abstr. No. 3055]. 2011.

[98] Kontos L, Schille C, Schweizer E, Geis-Gerstorfer J. Influence of surface treatment on the wear of solid zirconia. Acta Odontol Scand 2013; 71: 482-7.

[99] Janyavula S, Lawson N, Cakir D, Beck P, Ramp LC, Burgess JO The wear of polished and glazed zirconia against enamel. J Prosthet Dent 2013; 109: 22-9.

[100] Denry I, Kelly JR. Emerging ceramic-based materials for dentistry. J Dent Res 2014; 93(12): 1235-42. doi: 10.1177/0022034514 553627. Epub 2014

[101] Passos S, Nychka JA, Major P, Linke B, Flores-Mir C. In vitro fracture toughness of commercial Y-TZP ceramics: A systematic review. J Prosthodont 2014; doi: 10.1111/jopr. 12179. [Epub ahead of print]

[102] Passos S, Torrealba Y, Major P, Linke B, Flores-Mir C, Nychka JA. In vitro wear behavior of zirconia opposing enamel: a systematic review. J Prosthodont 2014; doi: 10.1111/jopr.12167. [Epub ahead of print].

[103] ISO. Dentistry-Ceramic Materials. ISO 6872. Int Organiz Standardiz 2008

[104] Tinschert J, Natt G, Mautsch W, Augthun M, Spikermann H Fracture resistance of lithium disilicate: alumina and zirconia-based three-unit fixed partial dentures: a laboratory study. Int J Prosthodont 2001; 14: 231-8. 
[105] Mehl A. Neue CAD/CAM-Systeme versprechen eine. Revolution DZW. Spezial 5/00.

[106] Kleinfelder JW, Ludwig K. Maximal bite force in patients with reduced periodontal tissue support with and without splinting. J Periodontol 2002; 73(10): 1184-7.

[107] Fontijn-Tekamp FA, Slagter A, Van Der Bilt A, et al. Biting and chewing in overdentures, full dentures, and natural dentitions. J Dent Res 2000; 79(7): 1519-24.

[108] Kelly JR. Ceramics in restorative and prosthetic dentistry. Annu Rev Mat Sci 1997; 27: 443-68.

[109] Kinsel RP, Lin D. Retrospective analysis of porcelain failures of metal ceramic crowns and fixed partial dentures supported by 729 implants in 152 patients: Patient-specific and implant-specific predictors of ceramic failure. J Prosthet Dent 2009; 101: 388-94.

[110] Dahl B, Ølio G. Wear of teeth and restorative materials, in O" wall B, Ka"yser AF, Carlsson GE, Eds. Prosthodontics. Principles and management strategies, Mosby-Wolfe, Ed. London. 1996: pp. 187200.

[111] Johansson A, Johansson A-K, Omar R, Carlsson GE. Rehabilitation of the worn dentition. J Oral Rehabilit 2008; 35: 548-66.

[112] Rekowa ED, Harsonob M, Janalc M, Thompsonb VP, Zhang G. Factorial analysis of variables influencing stress in all-ceramic crowns. Dent Mater 2006; 22: 125-32.

[113] Tinschert J, Natt G, Mohrbotter N, Spiekermann H, Schulze KA. Lifetime of alumina- and zirconia ceramics used for crown and bridge restorations. J Biomed Mater Res B Appl Biomat 2007; 80: 317-21.

[114] Schley J-S, Heusen N, Reich S, Fischer J, Haselhuhn K, Wolfart S. Survival probability of zirconia-based fixed dental prostheses up to 5 yr: a systematic review of the literature. Eur J Oral Sci 2010; 118: 443-50.

[115] Raigrodski AJ. Contemporary materials and technologies for allceramic fixed partial dentures: A review of the literature. J Prosthet Dent 2004; 92: 557-62.

[116] Eccles J. Tooth surface loss from abrasion, attrition and erosion. Dental Update 1982; 9: 373-81.

[117] Mehta SB, Banerji S, Millar BJ, Suarez-Feito JM. Current concepts on the management of tooth wear: part1. Assessment, treatment planning and strategies for the prevention and the passive management of tooth wear. Brit Dent J 2012; 212(1): 17-27.

[118] Bartlett DW. Retrospective long term monitoring of tooth wear using study models. Brit Dent J 2003; 194: 211-3.

[119] Heintze SD, Faouzi M, Rousson V, O"zcan M. Correlation of wear in vivo and six laboratory wear methods. Dent Mater 2012; 28: 961-73.

[120] Mormann WH, Stawarczyk B, Endera A, Senerc B, Attinc T, Mehla A. Wear characteristics of current aesthetic dental restorative $\mathrm{CAD} / \mathrm{CAM}$ materials: Two-body wear, gloss retention, roughness and Martens hardness. J Mechan Behav Biomed Mater 2013; 20: 113-25.

[121] Conrad HJ, Seong W, Pesun IJ. Current ceramic materials and systems with clinical recommendations: A systematic review. J Prosthet Dent 2007; 98: 389-404.

[122] Bayne SC. Dental restorations for oral rehabilitation: testing of laboratory properties versus clinical performance for clinical decision making. Review Article. J Oral Rehabilit 2007; 34: 92132.

[123] Denry I, Kelly J. State of the art of zirconia for dental applications. Dent Mater 2008; 24: 299-307.

[124] Carlsson GE. Critical review of some dogmas in prosthodontics. J Prosthodont Res 2009; 53: 3-10.

[125] DeLong R, Douglas W. Development of an artificial oral environment for the testing of dental restoratives: bi-axial force and movement control. J Dent Res 1983; 62: 32-6.

[126] Seligman DA, Pullinger A, Solberg WK. The prevalence of dental attrition and its association with factors of age, gender, occlusion, and TMJ symptomatology. J Dent Res 1988; 67: 1323-33.

[127] Nico HJ, Creugers Arnd F, Kayser AF, van't Hof MA. A metaanalysis of durability data on conventional fixed bridges. Comm Dent Oral Epidemiol 1994; 22: 448-52.

[128] Ban S. Polishing of zirconia full contour restoratives and antagonist wear. QDT 2012; 32: 1240-54.

[129] Sailer I, Gottnerb J, Kanel S, Hämmerle CHF. Randomized Controlled Clinical Trial of Zirconia-Ceramic and Metal-Ceramic Posterior Fixed Dental Prostheses: A 3-year Follow-up. Int J Prosthodont 2009; 22: 553-60.

Received: December 24, 2014

Revised: September 10, 2015

Accepted: September 29, 2015

(C) Elie E. Daou; Licensee Bentham Open.

This is an open access articles licensed under the terms of the Creative Commons Attribution-Non-Commercial 4.0 International Public License (CC BY-NC 4.0) (https://creativecommons.org/licenses/by-nc/4.0/legalcode), which permits unrestricted, non-commercial use, distribution and reproduction in any medium, provided that the work is properly cited. 